\title{
Inspiratory muscle strength training improves weaning outcome in failure to wean patients: a randomized trial
}

\author{
A Daniel Martin ${ }^{1,4^{*}}$, Barbara K Smith ${ }^{1}$, Paul D Davenport ${ }^{2}$, Eloise Harman ${ }^{3}$, Ricardo J Gonzalez-Rothi ${ }^{3}$, Maher Baz ${ }^{3}$, \\ A Joseph Layon ${ }^{3,4,5}$, Michael J Banner ${ }^{4}$, Lawrence J Caruso ${ }^{4}$, Harsha Deoghare ${ }^{1}$, Tseng-Tien Huang ${ }^{1}$, \\ Andrea Gabrielli ${ }^{4,5}$
}

\begin{abstract}
Introduction: Most patients are readily liberated from mechanical ventilation (MV) support, however, 10\% - 15\% of patients experience failure to wean (FTW). FTW patients account for approximately 40\% of all MV days and have significantly worse clinical outcomes. MV induced inspiratory muscle weakness has been implicated as a contributor to FTW and recent work has documented inspiratory muscle weakness in humans supported with MV.

Methods: We conducted a single center, single-blind, randomized controlled trial to test whether inspiratory muscle strength training (IMST) would improve weaning outcome in FTW patients. Of 129 patients evaluated for participation, 69 were enrolled and studied. 35 subjects were randomly assigned to the IMST condition and 34 to the SHAM treatment. IMST was performed with a threshold inspiratory device, set at the highest pressure tolerated and progressed daily. SHAM training provided a constant, low inspiratory pressure load. Subjects completed 4 sets of 6-10 training breaths, 5 days per week. Subjects also performed progressively longer breathing trials daily per protocol. The weaning criterion was 72 consecutive hours without MV support. Subjects were blinded to group assignment, and were treated until weaned or 28 days.

Results: Groups were comparable on demographic and clinical variables at baseline. The IMST and SHAM groups respectively received $41.9 \pm 25.5$ vs. $47.3 \pm 33.0$ days of MV support prior to starting intervention, $P=$ 0.36. The IMST and SHAM groups participated in $9.7 \pm 4.0$ and $11.0 \pm 4.8$ training sessions, respectively, $P=0.09$. The SHAM group's pre to post-training maximal inspiratory pressure (MIP) change was not significant $(-43.5 \pm$ 17.8 vs. $\left.-45.1 \pm 19.5 \mathrm{~cm} \mathrm{H} \mathrm{H}_{2} \mathrm{O}, P=0.39\right)$, while the IMST group's MIP increased $(-44.4 \pm 18.4$ vs. $-54.1 \pm 17.8 \mathrm{~cm}$ $\left.\mathrm{H}_{2} \mathrm{O}, \mathrm{P}<0.0001\right)$. There were no adverse events observed during IMST or SHAM treatments. Twenty-five of 35 IMST subjects weaned $(71 \%, 95 \%$ confidence interval $(C l)=55 \%$ to $84 \%)$, while 16 of $34(47 \%, 95 \% \mathrm{Cl}=31 \%$ to 63\%) SHAM subjects weaned, $P=.039$. The number of patients needed to be treated for effect was 4 ( $95 \% \mathrm{Cl}=$ 2 to 80$)$.
\end{abstract}

Conclusions: An IMST program can lead to increased MIP and improved weaning outcome in FTW patients compared to SHAM treatment.

Trial Registration: ClinicalTrials.gov: NCT00419458

\footnotetext{
* Correspondence: dmartin@phhp.ufl.edu

'Department of Physical Therapy, University of Florida, 1600 South West

Archer Road, PO Box 100154, Gainesville, FL, 32610, USA

Full list of author information is available at the end of the article
} 


\section{Introduction}

Failure to wean (FTW) from mechanical ventilation $(\mathrm{MV})$ is a significant clinical and economic problem. In 2003, approximately 300,00 patients required MV support for more than 96 hours in the USA and the estimated cost of these episodes was $\$ 16$ billion [1]. The number of patients requiring long-term MV support is increasing five times as rapidly as the number of hospital admissions [2] and many of these patients experience FTW.

The etiology of FTW is often complex, but an imbalance in the demand placed on the inspiratory muscles used to generate inspiratory pressure during tidal breathing and their maximal pressure generating capability $\left(\mathrm{Pi}_{\mathrm{br}} / \mathrm{Pi}_{\max }\right)$ has been implicated as a major contributor to this problem [3-5]. Numerous animal studies have documented ventilator-induced diaphragm dysfunction following as little as six hours of controlled MV [6-8], but less data examining the effects of MV on the human diaphragm are available. Knisely et al. [9] studied two children who had been ventilated for 7 and 45 days and qualitatively found profound atrophy of diaphragm muscle fibers following prolonged MV support. Levine et al. [10] documented approximately $55 \%$ atrophy in human diaphragms following 19 to 56 hours of controlled MV. Hermans et al. [11] recently reported marked reductions in magnetically stimulated transdiaphragmatic pressure in humans in the first week of MV support. Hussain et al. documented upregulation of catabolic process in human diaphragms following 15 to 276 hours of controlled MV [12], and Jaber et al. documented a $32 \%$ reduction in endotracheal tube pressure following magnetic diaphragm stimulation in humans following six days of MV support [13].

As an elevated $\mathrm{Pi}_{\mathrm{br}} / \mathrm{Pi}_{\max }$ ratio is thought to be a major contributor to weaning failure $[4,5]$ and MV has been shown to rapidly cause diaphragm weakness in humans, strength training the inspiratory muscles emerges as a possible treatment for FTW. Preoperative inspiratory muscle strength training (IMST) has been shown to reduce the incidence of postoperative respiratory complications in high-risk cardiac surgery patients [14] and has also been demonstrated to preserve postoperative inspiratory muscle strength following major abdominal surgery [15].

We $[16]$ and others $[17,18]$ have published successful case series and Caruso et al. published an unsuccessful [19] trial examining the effect of IMST on weaning outcome in FTW patients, but to date no adequately powered, randomized trial examining the effect of IMST on weaning outcome exists. We hypothesized that an IMST program, grounded in accepted principles of muscle strength training [20], coupled with progressively lengthening breathing trials (BT) would improve weaning outcome compared with the SHAM condition.

\section{Materials and methods}

After approval from the University of Florida Health Center Institutional Review Board (Federal wide Assurance FWA00005790), written informed consent was obtained from the patients or their legally designated surrogates. The trial was registered on Clinical Trials number NCT00419458. Patients were recruited from the adult medical, general surgical and burn ICUs of Shands Hospital at the University of Florida. Censuses of patients who were supported with MV were regularly queried and patients who had FTW with usual care were identified. Subjects were considered a FTW case when the patient failed to wean with usual care. Entry and exclusion criteria are shown in Table 1.

Subjects were studied from February 2004 until February 2009. The protocol was a single-blinded design with SHAM treatment. Subjects were blinded to their group assignment. Randomization was performed with a computerized random number generator and group assignments were sealed in opaque envelopes. Subjects were not randomized until they failed the initial BT.

\section{Maximal inspiratory pressure measurement}

Maximal inspiratory pressure (MIP) was measured on the first day of participation, every Monday and on days when the subjects attempted a 12-hour aerosol tracheotomy collar (ATC) trial. MIP was measured using the method of Caruso et al. [21]. Briefly, a one-way valve was attached to the patient's tracheostomy tube that allowed exhalation but blocked inspiration. The valve was connected to an electronic recording manometer and the patient was vigorously encouraged to inhale and exhale as forcefully as possible for 20 seconds. MIP measurements were repeated three times with a twominute rest period with MV support between each attempt; the most negative value was recorded.

\section{Inspiratory muscle strength training}

IMST was performed five days per week (Monday to Friday) with a threshold inspiratory muscle trainer (Threshold PEP; Respironics Inc; Murrysville, PA, USA), which provided a threshold inspiratory pressure load between -4 and $-20 \mathrm{cmH}_{2} \mathrm{O}$. The Threshold PEP device is marketed as an expiratory positive pressure device, but can provide an inspiratory threshold load if one inspires through the exhalation port. An inspiratory threshold training device is commercially available (Threshold IMT; Respironics Inc; Murrysville, PA, USA), but we found that many patients were unable to open the poppet valve at the lowest pressure setting $(8$ $\mathrm{cmH}_{2} \mathrm{O}$ ) on the Threshold IMT device. When 


\section{Table 1 Entry and exclusionary criteria}



$\mathrm{F}_{\mathrm{i}} \mathrm{O}_{2}$, fraction of inspired oxygen; $\mathrm{MV}$, mechanical ventilation; $\mathrm{P}_{\mathrm{a}} \mathrm{O}_{2}$, arterial pressure of oxygen; PEEP, positive end expiratory pressure; SIMV, synchronized intermittent mandatory ventilation.

performing IMST, the subjects were disconnected from the MV and the IMST device was attached to their tracheostomy tube with the cuff inflated. Subjects breathed room air during IMST. Subjects performed four sets of 6 to 10 breaths per day, with two minutes of rest with MV support between each set. The training device was set to the highest pressure setting that the subject could consistently open during inspiration, and was progressed daily as tolerated. Subjects were instructed to inhale and exhale as forcefully as possible during the IMST breaths. The IMST training program was based on clinical experience obtained prior to initiating this trial. Respiratory pressures at the tracheostomy tube were monitored during IMST and SHAM training with $\mathrm{CO}_{2} \mathrm{SMO}$ Plus respiratory monitors with Analysis Plus software (Respironics Inc; Murrysville, PA, USA) interfaced to a laptop computer.

\section{SHAM training}

The SHAM group used a resistive inspiratory muscle training device (Pflex; Respironics Inc; Murrysville, PA, USA) set on the largest opening. The Pflex device had a $3 \mathrm{~mm}$ hole drilled into the body, which further reduced the pressure required to generate airflow. Subjects performed SHAM training by being removed from the ventilator circuit and the training device was attached to the tracheostomy tube. Subjects breathed room air during SHAM treatment. Subjects performed four sets of 6 to 10 breaths, five days per week, and were instructed to breathe with long, slow inspiratory and expiratory efforts during training. SHAM subjects were given two minutes of rest with MV support between each set. IMST and SHAM treatments were normally conducted between $07.30 \mathrm{am}$ and $09.00 \mathrm{am}$, Monday through Friday.

\section{Breathing trials}

All subjects participated in progressively lengthening BTs with reduced or no MV support. Three types of BT were used: ATC, continuous positive airway pressure (CPAP) and reduced pressure support trials. Trials were conducted seven days per week, usually commencing around 09.00 am and only one trial per day was attempted. The initial BT was an ATC trial, and patients were allowed to breathe without MV support as long as tolerated. Subjects who tolerated this initial ATC trial for 72 hours were considered weaned and were not studied. Criteria for terminating BT included: 30 beats $/ \mathrm{min}$ or more increase in heart rate, systolic blood pressure above $180 \mathrm{mmHg}$ or below $90 \mathrm{mmHg}$, oxygen-hemoglobin saturation $\left(\mathrm{S}_{\mathrm{P}} \mathrm{O}_{2}\right)$ below $90 \%$ for five minutes, respiratory rate above 35 breaths/min for five minutes, serious dysrhythmias, if the patient requested to be returned to MV support or there was clinical evidence of respiratory distress (substernal retraction and sternocleidomastoid retraction, paradoxical breathing, or diaphoresis). 
The daily progression for the ATC trials was: one, two, three, four, six, nine, and twelve hours. The second ATC trial was targeted for the step below the duration the patient tolerated on their first ATC trial, not to exceed six hours. For example, if a patient tolerated four hours on the initial ATC trial, the second ATC trial duration was three hours, the next four hours and so on. When a subject failed an ATC trial, the next trial was the same duration. If a subject was unable to participate in ATC trials for several days, the ATC trial target duration was decreased by the number of steps equal to the number of days missed. When subjects successfully completed a 12-hour ATC trial, the next day they progressed to breathing without MV support as tolerated. If they tolerated the ATC trial for 72 hours, they were classified as weaned.

If the subject was unable to complete at least one hour on the initial ATC trial, the next day a one-hour CPAP trial was attempted. CPAP trials were progressed by one hour per day until reaching three hours and then the patient began the ATC trial schedule as above. If the patient was unable to complete the initial onehour CPAP trial, the next day they attempted a onehour reduced pressure support trial (no synchronized intermittent mandatory ventilation breaths, about 50\% of their baseline pressure support and baseline positive end expiratory pressure (PEEP)). If successful, the reduced pressure support trial duration was increased by one hour per day until reaching three hours whereupon they then began the CPAP and ATC trial progressions as detailed above.

Patients received usual nursing care during BT, but rehabilitation activities were withheld during BT until the patients could tolerate a six-hour ATC BT. Once patients could tolerate a six-hour BT, rehabilitation activity during BT was begun but reduced to approximately $50 \%$ of the normal duration and intensity until weaning. Breathing data during BT were monitored with ICU clinical bedside monitors and with a $\mathrm{CO}_{2} \mathrm{SMO}$ Plus respiratory monitor with Analysis Plus software (Respironics Inc; Murrysville, PA, USA) interfaced to a laptop computer. Prior to commencing the first and final BT, dynamic compliance and inspired and expired airway resistance were measured with the $\mathrm{CO}_{2} \mathrm{SMO}$ Plus respiratory monitors while the patients received their baseline level of MV support.

\section{Statistical analysis}

Categorical variables were analyzed with Chi-square tests. Between groups tests on continuous variables were analyzed with independent samples Student t tests. Within-group variables were analyzed with t tests for paired measures. Repeated measures analysis of variance (ANOVA) tests were used for variables with group, time factors, and group $\times$ times interactions. Cell means contrasts were used to explore differences when significant interactions were present in ANOVA. Statistical significance was set at $P<0.05$.

\section{Results}

The flow of subjects from evaluation to participation is shown in the CONSORT diagram (Figure 1). The randomization process resulted in groups that were equivalent on demographic factors, reasons for respiratory failure, treatment with renal replacement therapy, duration of MV prior to starting study intervention, duration of the initial ATC trial to failure, MIP, and other prognostic variables (Tables 2 and 3). Additionally, both groups experienced similar comorbidities during hospitalization before intervention (Table 4), received similar pharmacologic management during study intervention (Table 5), experienced similar complications during the study (Table 6), and underwent similar diagnostic and therapeutic procedures during study intervention (Table 7). Of note, $43 \%$ of the IMST subjects and $29 \%$ of SHAM subjects were dialysis dependent. Dialysis dependency has been associated with a reduced wean rate [22,23].

Six subjects did not fail during the initial ATC trial and were weaned without further intervention. These subjects were not randomized to treatment groups and were not included in the analysis. Three IMST subjects died during the 28-day treatment period, one withdrew from the study and two patients were transferred to other facilities before completing 28 days of treatment. These six subjects were classified as weaning failures. Three subjects in the SHAM group died during the 28day treatment period and three subjects were transferred to other facilities before completing 28 days. These six subjects were also classified as weaning failures.

Excluding the initial BT, the IMST group performed 330 trials and the SHAM group performed 382 trials. The IMST and SHAM groups successfully completed $77.0 \%$ and $73.0 \%$ of the BT, respectively $(P=0.23)$.

The IMST and SHAM groups participated in $9.7 \pm$ 4.0 and $11.0 \pm 4.8$ strength and SHAM training sessions, respectively $(P=0.09)$. The mean training pressure setting on the IMST device was $7.2 \pm 2.6$ vs. 12.8 $\pm 3.6 \mathrm{cmH}_{2} \mathrm{O}$ for the initial and final training bouts, respectively $(P<0.0001$, Table 3$)$. The SHAM group's modified training device was set at the largest orifice (lowest resistance setting) for all sessions. The IMST group developed $-9.54 \pm 3.70$ and $-14.52 \pm 4.59$ $\mathrm{cmH}_{2} \mathrm{O}$ of inspiratory pressure at the tracheotomy tube during the initial and final IMST bouts $(P=$ $0.0004)$. Corresponding training pressure values for the SHAM group were $-3.10 \pm 1.54$ and $-3.36 \pm 2.08$ $\mathrm{cmH}_{2} \mathrm{O}(P=0.86)$. The treatment $\times$ group interaction 


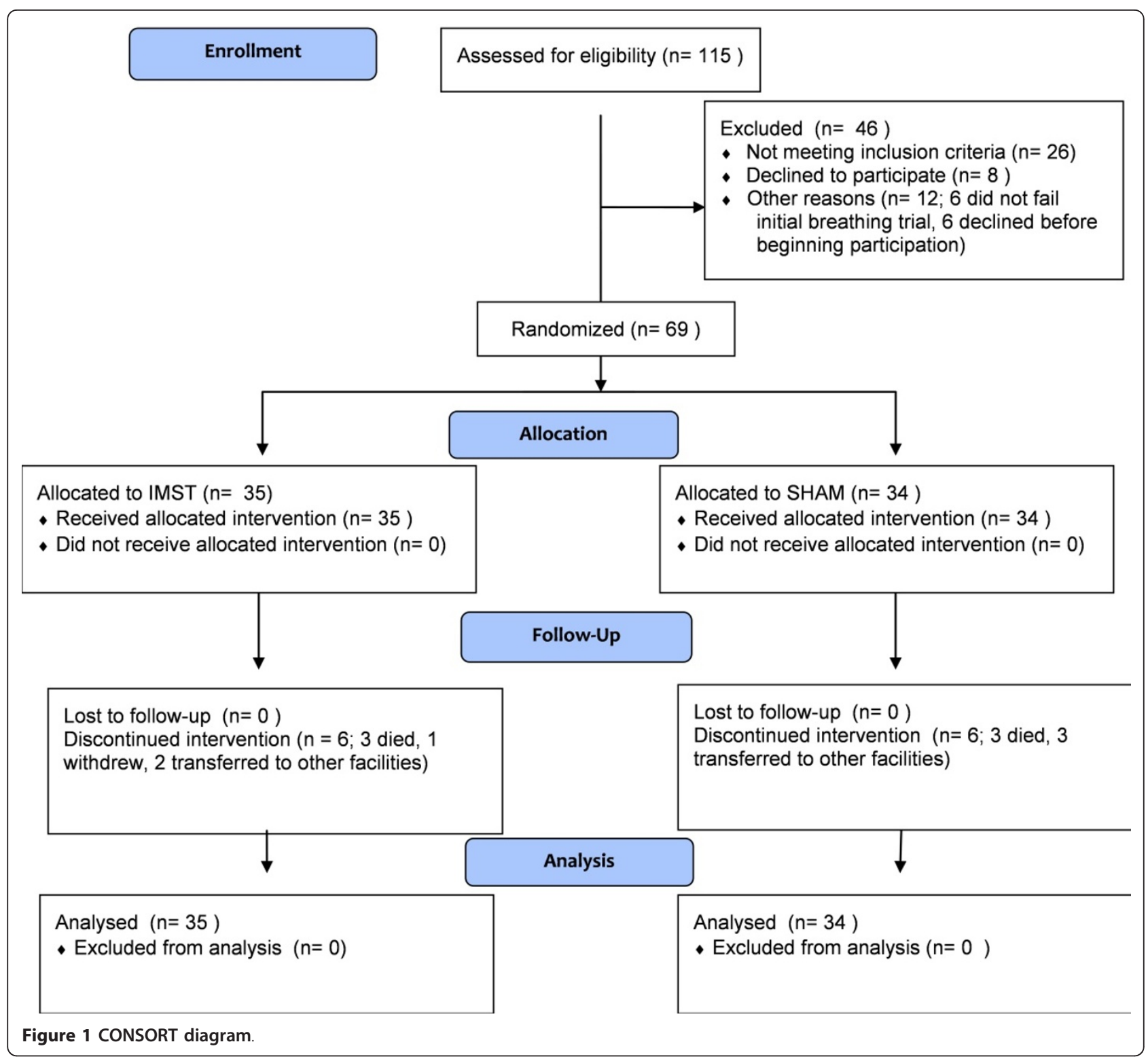

for pressure developed during training was significant $(P<0.0001)$. The SHAM group's pre to post-training MIP change was not significant $(-43.5 \pm 17.8$ vs. -45.1 $\left.\pm 19.5 \mathrm{cmH}_{2} \mathrm{O}, P=0.39\right)$, while the IMST group's MIP increased $\left(-44.4 \pm 18.4\right.$ vs. $-54.1 \pm 17.8, \mathrm{cmH}_{2} \mathrm{O}, \mathrm{P}<$ $0.0001)$. There were no adverse events observed during IMST or SHAM treatments.

Twenty-five of 35 IMST subjects weaned (71\%, 95\% confidence interval $(\mathrm{CI})=55 \%$ to $84 \%$ ), while 16 of 34 $(47 \%, 95 \% \mathrm{CI}=31 \%$ to $63 \%)$ SHAM subjects weaned $(P$ $=0.039)$. The number of patients needed to be treated for effect was 4 (95\% CI $=2$ to 80$)$.

In order to further explore the role of MIP changes in weaning outcome, we performed a post-hoc analysis on MIP using weaning outcome as the independent measure. The pre- and post-training MIP measures for the weaning success $(n=41)$ and failure $(n=28)$ groups were respectively; $-44.0 \pm 20.2$ and $-53.5 \pm 20.7 \mathrm{cmH}_{2} \mathrm{O}$ versus $-43.9 \pm 14.8$ and $-43.9 \pm 15.0 \mathrm{cmH}_{2} \mathrm{O}$. A repeated measures ANOVA revealed a significant outcome $\times$ time interaction and the change in MIP for the successfully weaned group was significantly greater than the failure to wean group $(P<0.0001)$.

\section{Discussion}

Our primary findings were that the IMST rehabilitation program rapidly improved MIP and improved weaning outcome compared with the SHAM condition. The weaning rate $(47 \%)$ achieved by the SHAM group was comparable with usual care conditions as reported in 
Table 2 Primary admission medical and surgical diagnoses

\begin{tabular}{|c|c|c|c|}
\hline Medical diagnosis & IMST & SHAM & TOTAL \\
\hline \multicolumn{4}{|l|}{ Cardiovascular } \\
\hline Acute congestive heart failure & 1 & . & 1 \\
\hline Myocardial infarct or unstable angina & 1 & & 1 \\
\hline \multicolumn{4}{|l|}{ Respiratory } \\
\hline Adult respiratory distress syndrome & 3 & . & 3 \\
\hline Interstitial disease & 1 & & 1 \\
\hline Pneumothorax & . & 1 & 1 \\
\hline Pulmonary vasculitis & & 1 & 1 \\
\hline \multicolumn{4}{|l|}{ Neurological } \\
\hline Acute intracranial hemorrhage & 1 & . & 1 \\
\hline \multicolumn{4}{|l|}{ Gastrointestinal } \\
\hline Pancreatitis & 1 & 1 & 2 \\
\hline \multicolumn{4}{|l|}{ Infectious/metabolic } \\
\hline Sepsis with shock & 2 & 2 & 4 \\
\hline TOTAL MEDICAL PATIENTS & 10 & 5 & 15 \\
\hline Surgical diagnosis & IMST & SHAM & TOTAL \\
\hline \multicolumn{4}{|l|}{ Cardiovascular } \\
\hline Abdominal aortic aneurysm repair & 2 & 2 & 4 \\
\hline Dissecting/ruptured aorta & 1 & 1 & 2 \\
\hline Cardiac valve replacement & . & 1 & 1 \\
\hline Peripheral artery bypass graft & 1 & & 1 \\
\hline Multiple simultaneous procedures & & 2 & 2 \\
\hline Other cardiovascular surgical procedures & 2 & & 2 \\
\hline \multicolumn{4}{|l|}{ Gastrointestinal } \\
\hline Esophageal surgery - for neoplasm & 5 & 2 & 7 \\
\hline Esophageal surgery - not for neoplasm & 1 & 1 & 2 \\
\hline Gastrointestinal surgery - for neoplasm & . & 1 & 1 \\
\hline Gastrointestinal surgery - not for neoplasm & 6 & 6 & 12 \\
\hline Hepatobiliary surgery - for neoplasm & 3 & 1 & 4 \\
\hline Hepatobiliary surgery - not for neoplasm & 1 & . & 1 \\
\hline \multicolumn{4}{|l|}{ Neurological } \\
\hline Craniotomy, not for neoplasm & & 4 & 4 \\
\hline Spinal surgery & & 2 & 2 \\
\hline Spinal cord injury & & 1 & 1 \\
\hline \multicolumn{4}{|l|}{ Orthopedic } \\
\hline Orthopedic surgery, not hip replacement & . & 2 & 2 \\
\hline Multiple simultaneous procedures & & 1 & 1 \\
\hline \multicolumn{4}{|l|}{ Miscellaneous } \\
\hline Liver transplantation & 2 & 1 & 3 \\
\hline Full-thickness burns/skin grafting & 1 & 1 & 2 \\
\hline TOTAL SURGICAL PATIENTS & 25 & 29 & 54 \\
\hline
\end{tabular}

IMST, inspiratory muscle strength training.

observational studies examining comparable FTW patients [24-26].

Other workers have shown that MIP is a poor predictor of extubation success [27-31]. Several differences between this study and the studies that found MIP to be a poor predictor of extubation outcome must be acknowledged: 1) studies that have shown MIP to be a poor predictor of extubation outcome examined intubated patients in the acute phase of MV support [28,31], whereas our subjects had received MV support for approximately six weeks prior to starting intervention and all of our patients had tracheotomies; 2) our selection criteria identified patients who had FTW because of inspiratory muscle weakness that was amenable to strength training; and 3) none of the studies that have evaluated MIP as an extubation predictor used any type of strength training program to increase MIP. Investigators have found that higher values of MIP are associated with improved weaning outcome in chronic FTW patients. Yang [31] reported in a cross-sectional study that the $\mathrm{Pi}_{\mathrm{br}} / \mathrm{Pi}_{\max }$ ratio of successfully weaned patients was lower than FTW patients. Carlucci et al. [5] have recently shown in an observational study with a group of long-term FTW patients similar to ours, that patients who eventually weaned, improved their MIP, and lowered the $\mathrm{Pi}_{\mathrm{br}} / \mathrm{Pi}_{\max }$ ratio, while those who FTW did not. Our findings also support a role for increased MIP in improved weaning outcomes.

We propose that respiratory muscle weakness is a greater contributor to failed weaning than fatigue. During failed BTs in FTW patients, respiratory distress is often clinically described as "fatigue". However, several authors have reported heightened respiratory muscle activity during failed BTs compared with stable respiratory muscle activity among patients who successfully completed BTs. For example, Teixeira et al. [32] measured a $50 \%$ increase in the work of breathing of FTW patients over the course of failed BTs, whereas successful patients maintained a constant work of breathing during the trials. Jubran et al. [33] reported similar findings and an absence of low-frequency fatigue during failed BT.

Alternatively, we hypothesize that inspiratory muscle weakness initiates a high proportional ventilatory drive requirement during unassisted $\mathrm{BT}$, when weakened inspiratory muscles must generate increased muscle tension in order to adequately ventilate the lungs. During MV support, a relatively low motor drive elicits large, ventilator-assisted tidal volume breaths. When an unsupported BT begins, a discrepancy between the elevated respiratory drive and afferent lung volume feedback can lead to an increased awareness of respiratory effort [34]. Perceived feedback errors will be addressed by further increases in respiratory motor drive, but the feedback discrepancy cannot be corrected by a highlydriven, weakened inspiratory pump that generates insufficient volume feedback [35].

Ongoing efferent-afferent feedback errors propel a positive feedback loop, resulting in the progressively higher levels of respiratory drive, inspiratory esophageal pressure, and work of breathing reported by others, and 


\begin{tabular}{|c|c|c|c|}
\hline & IMST $n=35$ & SHAM $n=34$ & $P$ value \\
\hline Age (years) & $65.6 \pm 11.7$ & $65.1 \pm 10.7$ & 0.86 \\
\hline Gender (male/female) & $16 / 19$ & $15 / 19$ & 0.42 \\
\hline $\begin{array}{l}\text { Number of smokers } \\
\text { Pack* years smoking history }\end{array}$ & $\begin{array}{c}12 \\
54 \pm 28\end{array}$ & $\begin{array}{c}11 \\
50 \pm 30\end{array}$ & $\begin{array}{l}0.86 \\
0.72\end{array}$ \\
\hline $\begin{array}{l}\text { Pre-albumin at study start } \\
\qquad(\mathrm{mg} / \mathrm{dL})\end{array}$ & $15.3 \pm 6.6$ & $15.4 \pm 6.3$ & 0.96 \\
\hline MV support days to start of study intervention & $41.9 \pm 25.5$ & $47.3 \pm 33.0$ & 0.36 \\
\hline $\begin{array}{c}\text { Total MV support days from hospital admission until end } \\
\text { of study participation }\end{array}$ & $57.3 \pm 29.5$ & $63.5 \pm 34.0$ & 0.46 \\
\hline Total study days & $14.4 \pm 8.1$ & $18.0 \pm 8.8$ & 0.10 \\
\hline SAPS $\|$ at study start & $33.5 \pm 8.6$ & $33.0 \pm 8.6$ & 0.83 \\
\hline \multicolumn{4}{|l|}{ Dynamic compliance } \\
\hline$\left(\mathrm{ml} / \mathrm{cm} \mathrm{H} \mathrm{H}_{2} \mathrm{O}\right)$ & $n=26$ & $n=27$ & ${ }^{\mathrm{a}} \mathrm{Tr}=0.93$ \\
\hline Pre-training & $53.9 \pm 18.3$ & $53.8 \pm 17.1$ & ${ }^{\mathrm{b}} \mathrm{Ti}=0.19$ \\
\hline Post-training & $57.8 \pm 19.5$ & $57.1 \pm 21.4$ & ${ }^{\mathrm{C}} \operatorname{Tr} \times \mathrm{Ti}=0.91$ \\
\hline \multicolumn{4}{|l|}{ Dynamic inspired airway resistance } \\
\hline$\left(\mathrm{cm} \mathrm{H}_{2} \mathrm{O} / \mathrm{L} / \mathrm{S}\right)$ & $n=26$ & $n=27$ & ${ }^{\mathrm{a}} \mathrm{Tr}=0.70$ \\
\hline Pre-training & $7.8 \pm 3.2$ & $7.1 \pm 3.0$ & ${ }^{\mathrm{b}} \mathrm{Ti}=0.12$ \\
\hline Post-training & $7.7 \pm 1.8$ & $8.8 \pm 3.0$ & ${ }^{\mathrm{c}} \operatorname{Tr} \times \mathrm{Ti}=0.08$ \\
\hline \multicolumn{4}{|l|}{ Dynamic expired airway resistance } \\
\hline$\left(\mathrm{cm} \mathrm{H}_{2} \mathrm{O} / \mathrm{L} / \mathrm{S}\right)$ & $n=26$ & $n=27$ & ${ }^{\mathrm{a}} \mathrm{Tr}=0.74$ \\
\hline Pre-training & $8.1 \pm 3.6$ & $7.3 \pm 3.1$ & ${ }^{\mathrm{b}} \mathrm{Ti}=0.16$ \\
\hline Post-training & $7.9 \pm 1.8$ & $9.1 \pm 3.4$ & ${ }^{\mathrm{c}} \mathrm{Tr} \times \mathrm{Ti}=0.07$ \\
\hline \multicolumn{4}{|l|}{ Renal function } \\
\hline $\begin{array}{c}\text { Blood urea nitrogen } \\
\qquad(\mathrm{mg} / \mathrm{dL})\end{array}$ & $35.6 \pm 15.6$ & $37.6 \pm 23.3$ & 0.67 \\
\hline $\begin{array}{l}\text { Creatinine }(\mathrm{mg} / \mathrm{dL}) \\
\text { (Includes subjects receiving renal replacement therapy) }\end{array}$ & $1.1 \pm 0.9$ & $1.0 \pm 0.7$ & 0.74 \\
\hline $\begin{array}{l}\text { Renal replacement therapy } \\
\mathrm{n}(\%)\end{array}$ & $15(43 \%)$ & $10(29 \%)$ & 0.33 \\
\hline Mean daily fluid balance (ml) & $118 \pm 964$ & $405 \pm 573$ & 0.14 \\
\hline \multicolumn{4}{|l|}{ Arterial blood gases on baseline MV support (initial day of study) } \\
\hline $\mathrm{pH}$ & $7.41 \pm 0.07$ & $7.42 \pm 0.06$ & 0.68 \\
\hline $\mathrm{P}_{\mathrm{a}} \mathrm{CO}_{2}$ (torr) & $42.9 \pm 7.4$ & $40.3 \pm 10.0$ & 0.20 \\
\hline $\mathrm{P}_{\mathrm{a}} \mathrm{O}_{2}$ (torr) & $113.8 \pm 48.0$ & $108.8 \pm 33.0$ & 0.60 \\
\hline $\mathrm{HCO}_{3}^{-}(\mathrm{mEq} / \mathrm{L})$ & $27.2 \pm 5.1$ & $26.0 \pm 2.9$ & 0.30 \\
\hline $\mathrm{P}_{\mathrm{a}} \mathrm{O}_{2} / \mathrm{F}_{\mathrm{i}} \mathrm{O}_{2}$ & $293 \pm 125$ & $278 \pm 97$ & 0.60 \\
\hline \multicolumn{4}{|l|}{ MV settings (initial day of study) } \\
\hline $\operatorname{SIMV}(\mathrm{br} / \mathrm{min})$ & $4.5 \pm 3.7$ & $3.8 \pm 2.2$ & 0.37 \\
\hline Pressure Support $\left(\mathrm{cm} \mathrm{H}_{2} \mathrm{O}\right)$ & $10.4 \pm 1.8$ & $10.0 \pm 3.4$ & 0.53 \\
\hline PEEP $\left(\mathrm{cm} \mathrm{H}_{2} \mathrm{O}\right)$ & $5.4 \pm 1.0$ & $5.8 \pm 1.6$ & 0.27 \\
\hline $\mathrm{F}_{\mathrm{i}} \mathrm{O}_{2}$ & $0.40 \pm 0.03$ & $0.40 \pm 0.004$ & 0.77 \\
\hline \multicolumn{4}{|l|}{ Study-related activity } \\
\hline Initial ATC trial duration to failure (hours) & $2.5 \pm 2.1$ & $3.1 \pm 3.1$ & 0.39 \\
\hline Number of study days patients were unable to participate & $3.4 \pm 5.0$ & $3.8 \pm 4.7$ & 0.77 \\
\hline (\% of study days) & $(16 \pm 21 \%)$ & $(15 \pm 18 \%)$ & 0.87 \\
\hline Pressure setting on IMST device $\left(\mathrm{cm} \mathrm{H}_{2} \mathrm{O}\right)$ & Pre $7.2 \pm 2.6$ & - & $<0.0001$ \\
\hline
\end{tabular}


Table 3 Demographic and medical data (Continued)

\begin{tabular}{|c|c|c|c|}
\hline Pressure developed at tracheotomy tube during treatment $\left(\mathrm{cmH}_{2} \mathrm{O}\right)$ & & & ${ }^{\mathrm{a}} \mathrm{Tr}=0.26$ \\
\hline Pre-training & $-9.54 \pm 3.70$ & $-3.10 \pm 1.54$ & ${ }^{\mathrm{b}} \mathrm{Ti}=0.0003$ \\
\hline Post-training & $-14.52 \pm 4.59$ & $-3.36 \pm 2.08$ & ${ }^{\mathrm{C}} \mathrm{Tr} \times \mathrm{Ti}<0.0001$ \\
\hline \multicolumn{4}{|l|}{ Data are mean \pm standard deviation. } \\
\hline \multicolumn{4}{|c|}{$\begin{array}{l}\text { ATC, aerosol tracheotomy collar; } \mathrm{F}_{\mathrm{i}} \mathrm{O}_{2} \text {, fraction of inspired oxygen; } \mathrm{HCO}_{3}{ }^{-} \text {, arterial bicarbonate concentration; IMST, inspiratory muscle strength training; } \mathrm{MV} \text {, } \\
\text { mechanical ventilation; } \mathrm{P}_{\mathrm{P}} \mathrm{CO}_{2} \text {, arterial pressure of carbon dioxide; } \mathrm{P}_{2} \mathrm{O}_{2} \text {, arterial pressure of oxygen; } \mathrm{P}_{2} \mathrm{O}_{2} / \mathrm{F}_{\mathrm{i}} \mathrm{O}_{2} \text {, ratio of arterial pressure of oxygen to inspired } \\
\text { oxygen fraction; PEEP, positive end expiratory pressure; SAPS II, new simplified acute physiology score; } \mathrm{SIMV} \text {, synchronized intermittent mandatory ventilation. }\end{array}$} \\
\hline \multicolumn{4}{|c|}{$\begin{array}{l}{ }^{a} \mathrm{Tr} \text {, treatment factor, }{ }^{b} \mathrm{Ti} \text {, time factor, }{ }^{c} \mathrm{Tr} \times \mathrm{TI} \text { treatment } \times \text { time interaction factor for two-way repeated measures analysis of variance on dynamic compliance, } \\
\text { dynamic inspired airway resistance, dynamic expired airway resistance and pressure developed at tracheotomy tube during training variables. All other variables }\end{array}$} \\
\hline
\end{tabular}

it may lead to clinical respiratory distress $[34,36]$. If this positive feedback cycle progresses to high levels of inspiratory muscle work, reflex sympathetic activation can occur, with shunting of blood from the periphery to the working respiratory muscles $[37,38]$. Elevated sympathetic activity is a probable cause of the tachycardia, hypertension, and diaphoresis frequently observed during failed BT in FTW patients. IMST has been shown to attenuate the sympathetic activation induced by high intensity inspiratory muscle work [39].

Strengthening the inspiratory muscles theoretically could correct the feedback discrepancy between respiratory drive and lung/chest expansion and may result in a lower perception of breathing effort. The perception of breathing effort has been experimentally altered by manipulations of inspiratory muscle strength. Campbell et al. [40] studied the perception of inspiring against standard inspiratory resistive loads before and after weakening the inspiratory muscles to about $30 \%$ of baseline with neuromuscular blockade. In the weakened state, subjects rated the effort of loaded breathing higher than in the unblocked condition. We [41] studied the effects of strengthening the inspiratory muscles on perception of inspiratory effort and respiratory drive in healthy subjects. Both the respiratory drive and the effort of breathing against standard inspiratory resistive loads were lower following a 50\% improvement in MIP. These findings support the hypothesis that the perception of inspiratory effort and respiratory drive are inversely proportional to inspiratory muscle strength and may help explain why an increased MIP contributed to weaning.

Whenever severely debilitated patients undergo muscle strength training, the possibility of exercise-induced muscle damage must be considered. Human $[42,43]$ studies have documented that long-term, high resistance inspiratory loading can induce diaphragm muscle fiber damage. Although we did not examine diaphragm samples for training-induced damage, we think that it is unlikely that the IMST program induced muscle damage for the following reasons: 1) the duration of muscle loading during each IMST training session was approximately one minute per day. In contrast, animal and
Table 4 Comorbidities between hospital admission and entering study

IMST SHAM

Cardiovascular

Angina

Atrial fibrillation

Bundle branch block

Arrhythmias requiring cardioversion

Congestive heart failure

Deep vein thrombosis

Myocardial infarction

Pacemaker

Pericarditis/endocarditis

Peripheral vascular disease/chronic wounds

Respiratory

$\begin{array}{lll}\text { Adult respiratory distress syndrome } & 2 & 4\end{array}$

Aspiration pneumonia

Bronchitis/bronchiectasis/chronic obstructive

pulmonary disease exacerbations

Pleural effusion

Pneumonia or tracheobronchitis

Pneumothorax

Pulmonary embolism

Hemothorax

Empyema

Respiratory arrest

Tracheal bleed

Bronchiolitis obliterans with organizing pneumonia

Cavitary respiratory lesions

Metabolic/Endocrine

Adrenal depletion

Diabetes mellitus

Hypothyroidism

Renal

Chronic renal failure (prior renal replacement therapy-dependence)

Acute renal failure (new renal replacement therapy dependence)

Renal insufficiency (no renal replacement therapy) $\quad 2 \quad 1$

Infections

Specific Organisms:

Candida albicans 
Table 4 Comorbidities between hospital admission and entering study (Continued)

\begin{tabular}{|c|c|c|}
\hline Cytomegalovirus & 4 & 4 \\
\hline Methicillin-resistant Staphylococcus aureus & 13 & 17 \\
\hline Vancomycin-resistant enterococci & 8 & 6 \\
\hline Pseudomonas & 13 & 13 \\
\hline Acid-fast bacillus smear positive & 1 & 0 \\
\hline Indwelling line-associated sepsis & 2 & 7 \\
\hline Urinary tract infection & 13 & 10 \\
\hline Sepsis with shock & 18 & 13 \\
\hline Sepsis without shock & 5 & 6 \\
\hline Gastrointestinal & & \\
\hline Ascites & 4 & 2 \\
\hline gastrointestinal hemorrhage & 10 & 11 \\
\hline Clostrium difficile colitis & 5 & 4 \\
\hline Ileus or gastroparesis & 2 & 3 \\
\hline Necrotic bowel & 4 & 1 \\
\hline Hepatic failure & 0 & 1 \\
\hline Pancreatitis & 5 & 1 \\
\hline Bowel perforation & 1 & 1 \\
\hline Abdominal or peritoneal hematoma & 5 & 3 \\
\hline Abdominal abscess & 2 & 3 \\
\hline Necrotic gallbladder/cholelithiasis & 3 & 2 \\
\hline Open abdomen & 3 & 2 \\
\hline Abdominal compartment syndrome & 0 & 1 \\
\hline Organ transplantation & & \\
\hline Liver & 2 & 1 \\
\hline Cardiac & 0 & 1 \\
\hline Renal & 1 & 0 \\
\hline Other & & \\
\hline Cardiac arrest & 6 & 7 \\
\hline Shock & 0 & 2 \\
\hline New cancer diagnosis & 11 & 9 \\
\hline Encephalitis & 0 & 1 \\
\hline Encephalopathy (unspecified etiology) & 5 & 1 \\
\hline Status epilepticus & 0 & 1 \\
\hline Subacute or chronic fractures & 1 & 3 \\
\hline Amputation & 0 & 1 \\
\hline Wound & 8 & 10 \\
\hline Wound or incisional dehiscence & 4 & 5 \\
\hline Myoclonus & 0 & 1 \\
\hline Critical illness myopathy (per physician) & 3 & 1 \\
\hline Critical illness myopathy (per diagnostic test) & 2 & 0 \\
\hline
\end{tabular}

IMST, inspiratory muscle strength training.

human studies have documented diaphragm damage with prolonged, high resistance loads, lasting $1.5[44,45]$ to 96 hours [46]. 2) Our IMST patients were able to inspire against increasing inspiratory loads on a daily basis. If the patients had been experiencing muscle soreness and contractile fiber damage from IMST, one would have expected diminished muscle performance, rather than increasing performance.
Table 5 Drug use during intervention by group

\begin{tabular}{|c|c|c|c|}
\hline & IMST & SHAM & $P$ value \\
\hline \multicolumn{4}{|l|}{ Anabolic steroids } \\
\hline n (\%) & $6(17 \%)$ & $9(26 \%)$ & 0.34 \\
\hline Mean drug days & $10.8 \pm 4.8$ & $15.6 \pm 7.3$ & 0.19 \\
\hline \multicolumn{4}{|l|}{ Antibacterial agents } \\
\hline n (\%) & 30 (86\%) & $29(85 \%)$ & 0.77 \\
\hline Mean drug days & $28 . \pm 27.8$ & $31.0 \pm 23.5$ & 0.71 \\
\hline \multicolumn{4}{|l|}{ Antiviral agents } \\
\hline n (\%) & $3(9 \%)$ & $1(3 \%)$ & - \\
\hline Mean drug days & $16.3 \pm 4.0$ & 6 & - \\
\hline \multicolumn{4}{|l|}{ Anti-arrhythmia agents } \\
\hline n (\%) & 13 (37\%) & 9 (26\%) & 0.34 \\
\hline Mean drug days & $16.1 \pm 11.0$ & $14.8 \pm 10.7$ & 0.77 \\
\hline \multicolumn{4}{|l|}{ Anti-hypertensive agents } \\
\hline n (\%) & 17 (49\%) & $20(59 \%)$ & 0.47 \\
\hline Mean drug days & $13.8 \pm 11.7$ & $15.3 \pm 12.9$ & 0.74 \\
\hline \multicolumn{4}{|l|}{ Bronchodilators } \\
\hline n (\%) & $16(46 \%)$ & $20(59 \%)$ & 0.28 \\
\hline Mean drug days & $12.2 \pm 7.5$ & $17.3 \pm 10.6$ & 0.43 \\
\hline \multicolumn{4}{|l|}{ Corticosteroids } \\
\hline n (\%) & $16(46 \%)$ & $13(38 \%)$ & 0.53 \\
\hline Mean drug days & $12.2 \pm 7.5$ & $10.8 \pm 14.4$ & 0.72 \\
\hline \multicolumn{4}{|l|}{ Diuretics } \\
\hline n (\%) & $21(60 \%)$ & $23(68 \%)$ & 0.47 \\
\hline Mean drug days & $10.6 \pm 6.6$ & $11.0 \pm 9.4$ & 0.88 \\
\hline \multicolumn{4}{|l|}{ Anti-glycemic agents } \\
\hline n (\%) & $24(69 \%)$ & $28(82 \%)$ & 0.18 \\
\hline Mean drug days & $13.5 \pm 9.1$ & $14.3 \pm 11.1$ & 0.77 \\
\hline \multicolumn{4}{|c|}{ Immune suppression agents } \\
\hline n (\%) & $3(9 \%)$ & $3(9 \%)$ & 0.70 \\
\hline Mean drug days & $10.3 \pm 14.4$ & $3.7 \pm 3.8$ & 0.48 \\
\hline \multicolumn{4}{|l|}{ Neuromuscular blockers } \\
\hline n (\%) & $1(3 \%)$ & $1(3 \%)$ & - \\
\hline Mean drug days & 2.0 & 2.0 & - \\
\hline \multicolumn{4}{|c|}{ Narcotic analgesic agents } \\
\hline n (\%) & $30(86 \%)$ & $26(76 \%)$ & 0.33 \\
\hline Mean drug days & $12.4 \pm 9.8$ & $13.9 \pm 8.7$ & 0.55 \\
\hline \multicolumn{4}{|l|}{ Sedatives } \\
\hline n (\%) & 27 (77\%) & $24(71 \%)$ & 0.42 \\
\hline Mean drug days & $13.4 \pm 13.0$ & $11.3 \pm 9.1$ & 0.50 \\
\hline \multicolumn{4}{|l|}{ Vasopressors } \\
\hline n (\%) & $5(14 \%)$ & $8(24 \%)$ & 0.33 \\
\hline Mean drug days & $3.8 \pm 4.7$ & $3.1 \pm 3.8$ & 0.78 \\
\hline \multicolumn{4}{|l|}{ Beta-blockers } \\
\hline n (\%) & 31 (89\%) & 29 (85\%) & 0.96 \\
\hline Mean drug days & $19.6 \pm 20.9$ & $22.0 \pm 21.6$ & 0.66 \\
\hline
\end{tabular}

IMST, inspiratory muscle strength training; $\mathrm{n}$, number of subjects taking that category of drug, followed by the percent of the group taking that drug category. $P$ values for proportions were calculated with chi square, corrected with Yate's correction for cells with five or less subjects. Mean drug days = mean number ( \pm standard deviation) of drug days for the subjects taking that category of drugs. For example, if a patient took two different antibiotics for four days, that patient would have accumulated eight drug days for the antibiotic category. Drug days were tested with unpaired T tests. 
Table 6 Complications occurring during intervention period

\begin{tabular}{|c|c|c|}
\hline & IMST & SHAM \\
\hline \multicolumn{3}{|l|}{ Cardiovascular } \\
\hline New angina diagnosis & 1 & 1 \\
\hline Deep vein thrombosis & 1 & 4 \\
\hline Myocardial infarction & 0 & 2 \\
\hline Pericardial effusion & 0 & 2 \\
\hline Hypertensive crisis & 10 & 4 \\
\hline \multicolumn{3}{|l|}{ Respiratory } \\
\hline Aspiration pneumonia & 3 & 1 \\
\hline Pneumonia or tracheobronchitis & 13 & 13 \\
\hline Pneumothorax & 0 & 1 \\
\hline Pleural effusion & 9 & 3 \\
\hline Mucus plug & 1 & 3 \\
\hline Other & 2 & 7 \\
\hline \multicolumn{3}{|l|}{ Infections } \\
\hline Vancomycin-resistant enterococci & 11 & 4 \\
\hline Methicillin-resistant staphylococcus aureus & 6 & 4 \\
\hline Cytomegalovirus & 1 & 2 \\
\hline Indwelling line-associated sepsis & 6 & 5 \\
\hline Urinary tract infection & 13 & 7 \\
\hline Sepsis with shock & 6 & 2 \\
\hline Sepsis without shock & 6 & 7 \\
\hline Other & 10 & 9 \\
\hline \multicolumn{3}{|l|}{ Gastrointestinal } \\
\hline Ascites & 1 & 0 \\
\hline Clostridium difficile colitis & 2 & 0 \\
\hline Gastrointestinal hemorrhage & 7 & 6 \\
\hline Hepatic failure & 0 & 1 \\
\hline \multicolumn{3}{|l|}{ Renal } \\
\hline Acute renal insufficiency & 1 & 0 \\
\hline Renal failure & 2 & 1 \\
\hline \multicolumn{3}{|l|}{ Other } \\
\hline Tracheal bleeding & 2 & 4 \\
\hline Cardiac arrest/cardiopulmonary resuscitation & 2 & 4 \\
\hline Death & 3 & 3 \\
\hline
\end{tabular}

IMST, inspiratory muscle strength training.

Our results are encouraging, but limitations must be acknowledged. The weaning results were significant, but this was a single site study with a relatively small sample size. Our IMST method is not suitable for all FTW patients. Patients must be sufficiently alert to cooperate with IMST, and patients whose FTW etiology is not the result of treatable inspiratory muscle weakness are unlikely to benefit from IMST. Our subjects were recruited primarily from surgical ICUs, with approximately $22 \%$ of the subjects treated in the medical ICU.

\section{Conclusions}

In conclusion, we found an improved MIP and weaning outcome with IMST compared with SHAM training in
Table 7 Diagnostic and therapeutic procedures performed during study

\begin{tabular}{|c|c|c|}
\hline & IMST & SHAM \\
\hline \multicolumn{3}{|l|}{ Imaging } \\
\hline Computerized tomography scan & 23 & 18 \\
\hline Echocardiogram & 4 & 3 \\
\hline Endoscopy, lower & 0 & 2 \\
\hline Endoscopy, upper & 3 & 3 \\
\hline Diaphragm movement test & 2 & 2 \\
\hline Electroencephalogram & 0 & 1 \\
\hline Venous Doppler test & 10 & 9 \\
\hline Other & 7 & 6 \\
\hline \multicolumn{3}{|l|}{ Lines and Tubes } \\
\hline Abdominal drain & 10 & 1 \\
\hline Central venous catheter & 22 & 19 \\
\hline Chest tube & 23 & 26 \\
\hline Gastrostomy tube & 7 & 10 \\
\hline Jejunostomy/gastro jejunum tube & 14 & 8 \\
\hline Peripherally inserted central catheter line & 35 & 47 \\
\hline Other & 28 & 33 \\
\hline \multicolumn{3}{|l|}{ Medical therapy } \\
\hline Bronchoscopy & 26 & 42 \\
\hline Renal replacement treatments & 111 & 62 \\
\hline Thoracentesis & 3 & 0 \\
\hline Transfusion, blood (units) & 81 & 132 \\
\hline Transfusion, other blood products & 6 & 35 \\
\hline Wound debridement & 1 & 1 \\
\hline Other & 8 & 14 \\
\hline \multicolumn{3}{|l|}{ Surgery } \\
\hline Abdominal & 3 & 1 \\
\hline Head/neck & 1 & 3 \\
\hline Vascular & 1 & 1 \\
\hline Thoracic & 0 & 3 \\
\hline Other & 3 & 5 \\
\hline
\end{tabular}

IMST, inspiratory muscle strength training.

medically complex, long-term FTW patients. IMST is a clinically practical and safe method to improve weaning outcome in selected FTW patients.

\section{Key messages}

- IMST can rapidly increase MIP in medically complex, long-term FTW patients.

- IMST, in conjunction with BT, can increase the number of FTW patients weaned versus SHAM training plus BT.

\section{Abbreviations}

ANOVA: analysis of variance; ATC: aerosol tracheotomy collar; BT: breathing trials; Cl: confidence interval; CPAP: continuous positive airway pressure; FTW: failure to wean; IMST: inspiratory muscle strength training; MIP: maximal inspiratory pressure; MV: mechanical ventilation; PEEP: positive end expiratory pressure; $\mathrm{Pi}_{\mathrm{br}} / \mathrm{Pi}_{\text {max }}$ : ratio of inspiratory tidal breathing pressure to maximal inspiratory pressure; $\mathrm{S}_{\mathrm{p}} \mathrm{O}_{2}$ : oxygen-hemoglobin saturation. 


\section{Acknowledgements}

Drs Martin, Gabrielli, Caruso, Harman, Baz, Davenport and Gonzalez-Rothi received salary support from the $\mathrm{NIH}$ grant. Smith received training support from $\mathrm{NIH}$ T32 HD043730. Respironics, Inc provided some of the $\mathrm{CO}_{2} \mathrm{SMO}+$ respiratory monitors used in the study. The authors would like to thank Anita Yeager (Dept of Anesthesiology) for editorial assistance. The authors would also like to thank the Nursing and Respiratory Therapy staffs, (in particular, Jeff Majeski, RRT and Steve Bonnet, RRT) for their patience and assistance with this work. Role of the Sponsor: The funding organizations (NIH and Respironics) had no role in the design and conduct of the study; in the collection, analysis, and interpretation of the data; or in the preparation, review, or approval of the manuscript.

\section{Author details}

'Department of Physical Therapy, University of Florida, 1600 South West Archer Road, PO Box 100154, Gainesville, FL, 32610, USA. ²Department of Physiological Sciences, University of Florida, 1600 South West Archer Road, PO Box 100144, Gainesville, FL, 32610, USA. ${ }^{3}$ Department of Medicine, Division of Pulmonary, Critical Care and Sleep Medicine University of Florida, 1600 South West Archer Road, PO Box 100225, Gainesville, FL, 32610, USA. ${ }^{4}$ Department of Anesthesiology, Division of Critical Care Medicine, University of Florida, 1600 South West Archer Road, PO Box 100254, Gainesville, FL, 32610, USA. ${ }^{5}$ Department of Surgery, University of Florida, 1600 South West Archer Road, PO Box 100129, Gainesville, FL, 32610, USA.

\section{Authors' contributions}

ADM had full access to all of the data in the study and takes responsibility for the integrity of the data and the accuracy of the data analysis. ADM, Gabrielli, MBanner, LJC, PD, EH and RJG contributed to study concept and design. ADM, BKS, TH and HD contributed to acquisition of data. ADM, AG, PD, MBanner, EH, MBaz, RJG and BKS contributed to analysis and interpretation of data. ADM, BKS, MBanner, RJG and AJL contributed to drafting of the manuscript. AG, PD, MBanner, EH, MB, HD, TH, RJG and AJL contributed to critical revision of the manuscript for important intellectual content. ADM, BKS, HD and TH contributed to statistical analysis. ADM obtained funding. This project was supported by NIH R01HD42705 to ADM. AJL, MBanner, LJC and MBaz contributed to administrative, technical, or material support. ADM, AG, LJC, EH, AJL, MBaz and RJG contributed to study supervision.

\section{Competing interests}

The University of Florida and Drs Martin, Gabrielli and Banner have applied for a patent to modify clinical mechanical ventilators to provide threshold inspiratory muscle training to patients receiving mechanical ventilation support.

Received: 24 November 2010 Revised: 3 February 2011

Accepted: 7 March 2011 Published: 7 March 2011

\section{References}

1. Zilberberg MD, Luippold RS, Sulsky S, Shorr AF: Prolonged acute mechanical ventilation, hospital resource utilization, and mortality in the United States. Crit Care Med 2008, 36:724-730.

2. Zilberberg MD, de Wit M, Pirone JR, Shorr AF: Growth in adult prolonged acute mechanical ventilation: Implications for healthcare delivery*. Crit Care Med 2008, 1451-1455.

3. Purro A, Appendini L, De Gaetano A, Gudjonsdottir M, Donner CF, Rossi A: Physiologic determinants of ventilator dependence in long-term mechanically ventilated patients. Am J Respir Crit Care Med 2000, 161:1115-1123.

4. Vassilakopoulos T, Zakynthinos S, Roussos C: The tension-time index and the frequency/tidal volume ratio are the major pathophysiologic determinants of weaning failure and success. Am J Respir Crit Care Med 1998, 158:378-385

5. Carlucci A, Ceriana P, Prinianakis G, Fanfulla F, Colombo R, Nava S: Determinants of weaning success in patients with prolonged mechanical ventilation. Crit Care 2009, 13:R97.

6. DeRuisseau KC, Shanely RA, Akunuri N, Hamilton MT, Van Gammeren D, Zergeroglu AM, McKenzie M, Powers SK: Diaphragm unloading via controlled mechanical ventilation alters the gene expression profile. Am J Respir Crit Care Med 2005, 172:1267-1275.
7. Gayan-Ramirez G, de Paepe K, Cadot P, Decramer M: Detrimental effects of short-term mechanical ventilation on diaphragm function and IGF-I mRNA in rats. Intensive Care Med 2003, 29:825-833.

8. Vassilakopoulos T: Ventilator-induced diaphragm dysfunction: the clinical relevance of animal models. Intensive Care Med 2008, 34:7-16.

9. Knisely AS, Leal SM, Singer DB: Abnormalities of diaphragmatic muscle in neonates with ventilated lungs. J Pediatr 1988, 113:1074-1077.

10. Levine S, Nguyen T, Taylor N, Friscia ME, Budak MT, Rothenberg P, Zhu J, Sachdeva R, Sonnad S, Kaiser LR, Rubinstein NA, Powers SK, Shrager JB: Rapid disuse atrophy of diaphragm fibers in mechanically ventilated humans. N Engl J Med 2008, 358:1327-1335.

11. Hermans G, Agten A, Testelmans D, Decramer M, Gayan-Ramirez G: Increased duration of mechanical ventilation is associated with decreased diaphragmatic force: a prospective observational study. Crit Care 2010, 14:R127.

12. Hussain SN, Mofarrahi M, Sigala I, Kim HC, Vassilakopoulos T, Maltais F, Bellenis I, Chaturvedi R, Gottfried SB, Metrakos P, Danialou G, Matecki S, Jaber S, Petrof BJ, Goldberg P: Mechanical Ventilation-induced Diaphragm Disuse in Humans Triggers Autophagy. Am J Respir Crit Care Med 2010, 182:1377-1386.

13. Jaber S, Petrof BJ, Jung B, Chanques G, Berthet JP, Rabuel C, Bouyabrine H, Courouble P, Koechlin-Ramonatxo C, Sebbane M, Similowski T, Scheuermann V, Mebazaa A, Capdevila X, Mornet D, Mercier J, Lacampagne A, Philips A, Matecki S: Rapidly Progressive Diaphragmatic Weakness and Injury during Mechanical Ventilation in Humans. Am J Respir Crit Care Med 2011, 183:364-371.

14. Hulzebos EH, Helders PJ, Favie NJ, De Bie RA, Brutel de la Riviere A, Van Meeteren NL: Preoperative intensive inspiratory muscle training to prevent postoperative pulmonary complications in high-risk patients undergoing CABG surgery: a randomized clinical trial. JAMA 2006, 296:1851-1857.

15. Kulkarni S, Fletcher E, McConnell A, Poskitt K, Whyman M: Pre-operative inspiratory muscle training preserves postoperative inspiratory muscle strength following major abdominal surgery - a randomised pilot study. Ann R Coll Surg Engl 2010.

16. Martin AD, Davenport PD, Franceschi AC, Harman E: Use of inspiratory muscle strength training to facilitate ventilator weaning: a series of 10 consecutive patients. Chest 2002, 122:192-196.

17. Aldrich TK, Karpel JP: Inspiratory muscle resistive training in respiratory failure. Am Rev Respir Dis 1985, 131:461-462.

18. Sprague SS, Hopkins PD: Use of inspiratory strength training to wean six patients who were ventilator-dependent. Phys Ther 2003, 83:171-181.

19. Caruso P, Denari SD, Ruiz SA, Bernal KG, Manfrin GM, Friedrich C, Deheinzelin D: Inspiratory muscle training is ineffective in mechanically ventilated critically ill patients. Clinics 2005, 60:479-484.

20. American College of Sports Medicine Position Stand. Exercise and physical activity for older adults. Med Sci Sports Exerc 1998, 30:992-1008.

21. Caruso P, Friedrich C, Denari SD, Ruiz SA, Deheinzelin D: The unidirectional valve is the best method to determine maximal inspiratory pressure during weaning. Chest 1999, 115:1096-1101.

22. Nozawa E, Azeka E, Ignez ZM, Feltrim Z, Auler Junior JO: Factors associated with failure of weaning from long-term mechanical ventilation after cardiac surgery. Int Heart J 2005, 46:819-831.

23. Chao DC, Scheinhorn DJ, Stearn-Hassenpflug M: Impact of renal dysfunction on weaning from prolonged mechanical ventilation. Crit Care 1997, 1:101-104.

24. Scheinhorn DJ, Hassenpflug M, Artinian BM, LaBree L, Catlin JL: Predictors of weaning after 6 weeks of mechanical ventilation. Chest 1995, 107:500-505.

25. Scheinhorn DJ, Hassenpflug MS, Votto JJ, Chao DC, Epstein SK, Doig GS, Knight EB, Petrak RA: Post-ICU mechanical ventilation at 23 long-term care hospitals: a multicenter outcomes study. Chest 2007, 131:85-93.

26. Pilcher DV, Bailey MJ, Treacher DF, Hamid S, Williams AJ, Davidson AC: Outcomes, cost and long term survival of patients referred to a regional weaning centre. Thorax 2005, 60:187-192.

27. Capdevila XJ, Perrigault PF, Perey PJ, Roustan JP, d'Athis F: Occlusion pressure and its ratio to maximum inspiratory pressure are useful predictors for successful extubation following T-piece weaning trial. Chest 1995, 108:482-489.

28. Yang $\mathrm{KL}$, Tobin MJ: A prospective study of indexes predicting the outcome of trials of weaning from mechanical ventilation. $N$ Engl I Med 1991, 324:1445-1450. 
29. Nemer SN, Barbas CS, Caldeira JB, Guimaraes B, Azeredo LM, Gago R, Souza PC: Evaluation of maximal inspiratory pressure, tracheal airway occlusion pressure, and its ratio in the weaning outcome. J Crit Care 2009, 24:441-446.

30. Bruton A: A pilot study to investigate any relationship between sustained maximal inspiratory pressure and extubation outcome. Heart Lung 2002, 31:141-149.

31. Yang KL: Inspiratory pressure/maximal inspiratory pressure ratio: a predictive index of weaning outcome. Intensive Care Med 1993, 19:204-208.

32. Teixeira C, Teixeira PJ, de Leon PP, Oliveira ES: Work of breathing during successful spontaneous breathing trial. J Crit Care 2009, 24:508-514.

33. Jubran A, Grant BJ, Laghi F, Parthasarathy S, Tobin MJ: Weaning prediction: esophageal pressure monitoring complements readiness testing. Am J Respir Crit Care Med 2005, 171:1252-1259.

34. O'Donnell DE, Banzett RB, Carrieri-Kohlman V, Casaburi R, Davenport PW, Gandevia SC, Gelb AF, Mahler DA, Webb KA: Pathophysiology of dyspnea in chronic obstructive pulmonary disease: a roundtable. Proc Am Thorac Soc 2007, 4:145-168.

35. Scano G, Innocenti-Bruni G, Stendardi L: Do obstructive and restrictive lung diseases share common underlying mechanisms of breathlessness? Respir Med 2010, 104:925-933.

36. Mioxham J, Jolley C: Breathlessness, fatigue and the respiratory muscles. Clin Med 2009, 9:448-452.

37. St Croix CM, Morgan BJ, Wetter TJ, Dempsey JA: Fatiguing inspiratory muscle work causes reflex sympathetic activation in humans. J Physiol 2000, 529(Pt 2):493-504.

38. Sheel AW, Derchak PA, Morgan BJ, Pegelow DF, Jacques AJ, Dempsey JA: Fatiguing inspiratory muscle work causes reflex reduction in resting leg blood flow in humans. J Physiol 2001, 537:277-289.

39. Witt JD, Guenette JA, Rupert JL, McKenzie DC, Sheel AW: Inspiratory muscle training attenuates the human respiratory muscle metaboreflex. J Physiol 2007, 584:1019-1028.

40. Campbell EJ, Gandevia SC, Killian KJ, Mahutte CK, Rigg JR: Changes in the perception of inspiratory resistive loads during partial curarization. $J$ Physiol 1980, 309:93-100.

41. Kellerman BA, Martin AD, Davenport PW: Inspiratory strengthening effect on resistive load detection and magnitude estimation. Med Sci Sports Exerc 2000, 32:1859-1867.

42. Fuster A, Sauleda J, Sala E, Barcelo B, Pons J, Carrera M, Noguera A, Togores B, Agusti AG: Systemic inflammation after inspiratory loading in chronic obstructive pulmonary disease. Int J Chron Obstruct Pulmon Dis 2008, 3:149-153.

43. Orozco-Levi M, Lloreta J, Minguella J, Serrano S, Broquetas JM, Gea J: Injury of the human diaphragm associated with exertion and chronic obstructive pulmonary disease. Am J Respir Crit Care Med 2001, 164:1734-1739.

44. Wang X, Jiang TX, Road JD, Redenbach DM, Reid WD: Granulocytosis and increased adhesion molecules after resistive loading of the diaphragm. Eur Respir J 2005, 26:786-794.

45. Jiang TX, Reid WD, Road JD: Free radical scavengers and diaphragm injury following inspiratory resistive loading. Am J Respir Crit Care Med 2001, 164:1288-1294.

46. Reid WD, Belcastro AN: Time course of diaphragm injury and calpain activity during resistive loading. Am J Respir Crit Care Med 2000, 162:1801-1806.

doi:10.1186/cc10081

Cite this article as: Martin et al.: Inspiratory muscle strength training improves weaning outcome in failure to wean patients: a randomized trial. Critical Care 2011 15:R84.

\section{Submit your next manuscript to BioMed Central and take full advantage of:}

- Convenient online submission

- Thorough peer review

- No space constraints or color figure charges

- Immediate publication on acceptance

- Inclusion in PubMed, CAS, Scopus and Google Scholar

- Research which is freely available for redistribution

Submit your manuscript at www.biomedcentral.com/submit
C Biomed Central 